\title{
CONF- $9609131-1$
}

\section{GEOSTATISTICS AND COST-EFFECTIVE ENVIRONMENTAL REMEDIATION}

\author{
Christopher A. Rautman \\ Sandia National Laboratories \\ P. O. Box 5800; MS- 1324 \\ Albuquerque, New Mexico 87185 \\ USA
}

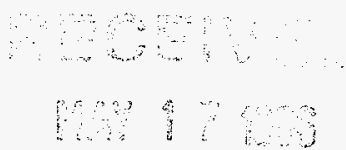

\section{Introduction}

Numerous sites within the U.S. Department of Energy (DOE) complex have been contaminated with various radioactive and hazardous materials by defense-related activities during the post-World War II era. The perception is that characterization and remediation of these contaminated sites will be too costly using currently available technology. Consequently, the DOE Office of Technology Development has funded development of a number of alternative processes for characterizing and remediating these sites. The former Feed-Materials Processing Center near Fernald, Ohio (USA), was selected for demonstrating several innovative technologies. Contamination at the Fernald site consists principally of particulate uranium and derivative compounds in surficial soil.

A field-characterization demonstration program was conducted during the summer of 1994 specifically to demonstrate the relative economic performance of seven proposed advanced-characterization tools for measuring uranium activity of in-situ soils. These innovative measurement technologies are principally radiation detectors of varied designs (table 1). Four industry-standard measurement technologies, including conventional, regulatory-agency-accepted soil sampling followed by laboratory geochemical analysis, were also demonstrated during the program for comparative purposes.

A risk-based economic-decision model has been used to evaluate the performance of these alternative characterization tools. The decision model computes the dollar value of an objective function for each of the different characterization approaches. The objective function is defined as the total cost to remediate the demonstration site, including the cost of characterization, the cost of treatment, and the expected cost of failure to clean the entire site to regulatory standards. The preferred characterization method is that which minimizes the value of the objective function.

Although this application of the methodology at the Fernald site involves a number of site- and situation-specific considerations, the cost-risk-benefit decision framework is completely general. The methodology not only can assist site operators to choose among engineering alternatives for site characterization and/or remediation, but also can provide an objective and quantitative basis for decisions with respect to the completeness of site characterization. The quantitative framework may also serve as a basis for more productive and focused discussions with regulatory agencies and other stakeholders in the environmental remediation arena.

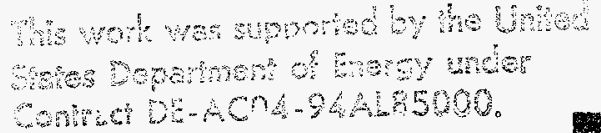




\section{DISCLAIMER}

Portions of this document may be illegible in electronic image products. Images are produced from the best available original document. 


\section{Economic Cost-Risk-Benefit Decision Framework}

The decision model employed at the Fernald field-demonstration program builds upon a comprehensive logical framework for economic-decision analysis that was outlined by Freeze and others (1990). The framework attempts to quantify the various costs, risks, and benefits associated with the design and implementation of a given engineering decision. What distinguishes the approach of Freeze and others from many other cost-benefit decision frameworks is the quantitative emphasis placed on economic risk: the likely costs that result from uncertainty regarding the ultimate performance of the system being evaluated. The entire analysis is denominated in currency units (dollars or otherwise), thus reducing all components of the analysis to a common reference familiar to business decision-makers. The goal of the economic-decision analysis is to maximize an objective function $\left(\Phi_{i}\right)$ that represents the overall monetary return associated with a given project. The objective function is computed as the net present value of all revenues or benefits resulting from the project, less all relevant expenses or costs including the expected cost of uncertain performance, for a reasonable number of engineering alternatives.

TABLE 1: Classification, brief description, and sampling costs of alternative characterization technologies demonstrated at the Fernald site. [All costs in U.S. dollars]

\begin{tabular}{|c|c|c|c|c|c|}
\hline ID & Technology Description & \multicolumn{2}{|c|}{ Detection Principle } & Total Cost & $\begin{array}{c}\text { Sample } \\
\text { Cost }\end{array}$ \\
\hline \multicolumn{6}{|c|}{ Advanced Field-Measurement Technologies } \\
\hline ATD & Alpha-track detector & passive & alpha particles & 10,131 & 87 \\
\hline Beta & Beta scintillometer & passive & beta particles & 15,391 & 167 \\
\hline EIC & Electret ionization chamber & passive & alpha particles & 9,337 & 92 \\
\hline GMH & $\begin{array}{c}\text { High-mount } \\
\text { gamma spectrometry }\end{array}$ & passive & gamma rays & 13,183 & 155 \\
\hline GML & $\begin{array}{l}\text { Low-mount } \\
\text { gamma spectrometry }\end{array}$ & passive & gamma rays & 13,669 & 155 \\
\hline ICP & $\begin{array}{l}\text { Laser-ablation } \\
\text { inductively coupled plasma } \\
\text { atomic emission spectrometry }\end{array}$ & active & $\begin{array}{l}\text { visible and } \\
\text { ultraviolet light }\end{array}$ & 22,540 & 272 \\
\hline LRAD & Long-range alpha detector & passive & alpha particles & 15,336 & 162 \\
\hline \multicolumn{6}{|c|}{ Industry-Standard Field-Screening Techniques } \\
\hline FID & FIDLER scintillometer & passive & gamma rays & 4,771 & 50 \\
\hline Lab & Mass spectroscopy & active & ionized elements & 35,055 & 340 \\
\hline NAD & NaI scintillometer & passive & gamma rays & 3,709 & 42 \\
\hline $\mathrm{XRF}$ & $\mathrm{X}$-ray fluorescence & active & photons & 9,588 & 99 \\
\hline
\end{tabular}

In the case of environmental remediation activities, there generally are no particular economic benefits to the site operator in the sense originally implied by Freeze and others. For example, there are no dollar inflows to the DOE that result directly from cleaning up the Fernald site. This functionally transforms the profit-maximization framework into a total-cost minimization exercise, which can be stated mathematically as follows:

$$
\text { Minimize: } \Phi_{i}=\text { Ctotal }_{i}=\text { Cchar }_{i}+\text { Ctreat }_{i}+E\left\{\text { Cfail }_{i}\right\}
$$

across the suite of $i$ different alternative characterization technologies. In equation (1), 
Ctotal $_{i}$ is the total cost associated with characterizing and remediating the site using characterization technology $i$. This cost is comprised of the cost of characterization $\left(C_{c h a r}\right)$, the cost of treatment $\left(\right.$ Ctreat $\left._{i}\right)$, and the expected cost of failure $\left(E\left\{C f a i l_{i}\right\}\right)$. The expected cost of failure is defined as:

$$
E\left\{\mathrm{Cfail}_{i}\right\}=\text { Pfail }_{i} \cdot \mathrm{Cfail}_{i}
$$

where $\mathrm{Pfail}_{i}$ is the probability of failure and $C f a i l_{i}$ is the cost incurred if that failure actually takes place. Uncertainty and economic risk enter the decision model through this probability of failure term. One minimizes the economic cost of a project by trading-off these different cost components against one another, and potentially, by trading costs (including risk costs) against variable benefits.

\section{Application to the Fernald 1994 Field Characterization Demonstration Program}

The 1994 Fernald field characterization demonstration program provides a near-ideal application of this form of economic-decision analysis. The problem is to choose a measurement technique for characterizing uranium contamination in soil from among a number of alternative characterization technologies. Some measurement technologies may be relatively inexpensive to operate, but the readings may be less accurate than the readings produced by a more expensive technology. Some technologies may be roughly comparable in costs, but may produce differing predictions of the contaminated region. A more conservative measurement technique, one which indicates more contamination than is actually present, may reduce the likelihood that the remediated site will fail to meet regulatory inspections, but at the increased cost of removing and treating soil that might have been left in place. Conversely, a less conservative measurement technique may suggest a lower initial remediation cost, but leave the operator exposed to a large potential liability if residual contamination is detected later. Additionally, because of the technology-development nature of the demonstration program, measurements of uranium contamination were also obtained using laboratory analytical methods currently accepted by the cognizant regulatory agencies. Thus, under the presumption that it is the regulator's perception of what is and what is not contaminated that is a prime determinant of environmental remediation success or failure, a reasonable model of ground truth is available as a benchmark against which to compare the other technologies that have been proposed as alternatives to current practices.

\subsection{SITE DESCRIPTION AND FIELD CHARACTERIZATION PROGRAM}

The 1994 Fernald field characterization demonstration program was conducted at a location know as the incinerator area. A simple combustion unit operated at this site from 1954 until 1979, and this incinerator burned combustible wastes generated from both plant administrative and process areas. Some of the process wastes contained low levels of radioactive materials, principally uranium, and particulate uranium was dispersed across nearby areas as an aerosol plume. Activities representing a mixture of both natural and depleted uranium vary from background of 5-10 picocuries per gram (pCi/g) to more than several thousand $\mathrm{pCi} / \mathrm{g}(\mathrm{DOE}, 1992)$. Other site characterization activities at 
the Fernald site have indicated that the bulk of the uranium above likely, but not yet final, action levels is present in the top 2 inches or so of the soil (Schilk and others, 1993; Rautman and others, 1995).

The 1994 demonstration program focused on a 2.9 -acre portion of the incinerator area. A generally regular grid consisting of a total of 85 sample locations on nested 60 , 30-, and 5-ft spacings was defined and marked in the field. All alternative technologies recorded measurements at these marked locations. Each technology was calibrated to a common set of native Fernald soils spiked with known levels of uranium; calibration beds were sampled and analyzed by laboratory mass spectroscopy techniques.

\subsection{IDENTIFICATION OF “CONTAMINATED” REGIONS}

We have assumed that excavation of contaminated soil at the Fernald site will take place using mechanical equipment, thus limiting somewhat the selectivity of excavation units. For purposes of this comparison, a selective remediation unit is presumed to consist of a square panel 10-ft by $10-\mathrm{ft}$ in size (approximately the width of a bulldozer blade) and 4 inches deep. This convention is consistent with previous geostatistical modeling of uranium contamination at Fernald (Rautman and others, 1994).

Because the uranium activity of each potential remediation unit, or parcel, has not been measured directly, it is necessary to compare both sampled and unsampled locations. We have used conventional variography and sequential gaussian simulation conditioned on the relevant characterization data (Deutsch and Journel, 1992) to model the exhaustive spatial distribution of uranium. The simulation methodology results in a suite of equally likely maps of contaminant distribution, all of which reflect the measured values at their spatial locations and all of which exhibit essentially the same statistical and spatial character as the data. This stochastic approach explicitly acknowledges that the models of contaminant distribution derived from the alternative characterization technologies and the model of true contamination derived from soil geochemistry are uncertain. With no a priori means of determining which of the many possible simulated models is the actual "true" map of uranium contamination, we "decide" to clean up all parcels that have an empirically determined (through post-processing the suite of simulations) probability of exceeding a specified action threshold greater than some probability level, $p$.

\subsection{ECONOMIC COSTS}

\subsubsection{Characterization Costs}

Actual costs for the characterization portion of the 1994 Fernald field demonstration program have been tabulated by Douthat and others (1995). These cost data are summarized in table 1. There is an order-of-magnitude variation in cost among the several technologies examined. The industry-standard field screening methods generally were significantly less expensive than the proposed alternative characterization technologies. Cost of completing the field survey using the newer, alternative-characterization technologies ranged from US $\$ 9,300$ to more than $\$ 22,500$. The currently accepted characterization method for regulatory purposes, consisting of soil sampling followed by conventional laboratory geochemical analysis was, in fact, the most expensive characterization 
method. The cost of completing the field survey and associated supporting measurements using soil sampling exceeded $\$ 35,000$.

\subsubsection{Treatment Costs}

Costs to treat Fernald soils selected for remediation via the various characterization techniques are somewhat more uncertain because a remediation technology has not yet been selected for the Fernald site. However, there are several treatment methods that involve roughly comparable costs of approximately $\$ 200$ per ton of soil processed. Adjusting this cost per ton for the volume and bulk density of a selective remediation unit results in a dollar cost of $\$ 437$ per contaminated panel.

\subsubsection{Failure Costs}

In the case of environmental remediation, "failure" essentially results from a misclassification error in predicting actual contaminant levels from some type of site characterization activity. Figure 1 illustrates this classification problem. The true contaminant concentration of any given parcel of land is assumed to be unknown. The site operator conducts site characterization and predicts that contamination level for all unsampled locations. Depending upon whether the predicted concentration, $Z$, is above or below a regulatory threshold or action level, $Z^{*}$, the operator will decide whether to remediate that parcel. Note that absolute accuracy of the prediction does not particularly matter. The remediation decision is based solely upon whether the prediction is that the parcel is above (contaminated) or below (not contaminated) the regulatory action level. It is the correctness of the remediation decision that matters, not the accuracy of the prediction itself.

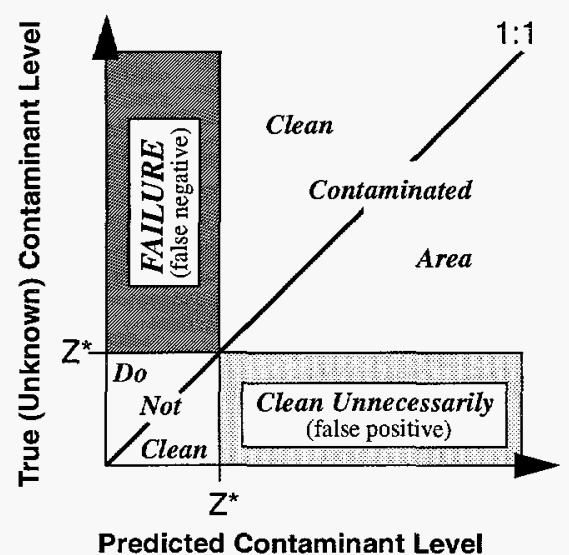

Figure 1. Classification problem for a contaminated site. Decision to remediate or leave as-is will be based upon a predicted contaminant level.
TABLE 2: Contingency table showing alternative costs of failure. [All values in US dollars]

\begin{tabular}{|c|c|c|}
\hline & $\begin{array}{l}\text { Small-Value } \\
\text { Failure }\end{array}$ & $\begin{array}{l}\text { Large-Value } \\
\text { Failure }\end{array}$ \\
\hline $\begin{array}{l}\text { Small No: } \\
\text { of Failures }\end{array}$ & $\$ a=437 /$ parcel & $\begin{array}{c}\$ \mathrm{~b}=2,000 / \\
\text { parcel }\end{array}$ \\
\hline $\begin{array}{l}\text { Large No. } \\
\text { of Failures }\end{array}$ & $\$ c=35,000$ & $\$ d=500,000$ \\
\hline $\begin{array}{l}{ }^{\dagger} \text { distinction s } \\
\text { geochemistr } \\
\ddagger \\
\text { fdistinction s } \\
\text { covering the }\end{array}$ & $\begin{array}{l}\text { twice the standard } \\
\text { analyses } \\
30 \text { percent of the } \\
\text { onstration site }\end{array}$ & $\begin{array}{l}\text { iation of the soil } \\
6 \text { parcels }\end{array}$ \\
\hline
\end{tabular}

After the site operator determines that the site has been cleaned-up to regulatory standards, we assume that the regulatory agency examines some or all of the site area and makes its own determination of whether or not the various remaining parcels are below 
the regulatory threshold. Although the in-fact "true" concentration for a given panel may still be unknown (even unknowable) to the regulatory agency, we assume that the agency's determination is what matters in determining success or failure. If the regulatory agency's determination is that the parcel is still above threshold - that the parcel has been misclassified (a false negative figure 1) -we count the site characterization-remediation effort a failure.

Note that not all misclassification errors count as failures under this scenario. If the site operator conducts remediation activities, when in fact a parcel is not above threshold, there has been a misclassification error. However, this false positive (figure 1) does not constitute regulatory failure, because the parcel is presumed clean following treatment. There are economic costs to this second type of misclassification error; however, the cost of failure is not one of them.

Actual costs of failure for the Fernald site are more problematical than the costs involved in either site characterization or remediation. We have defined a cost of failure, Cfail, that varies according to the degree of that failure according to the contingency table given as table 2. A "small-value" failure is defined as one in which the contaminant concentration of a given "uncontaminated" parcel actually exceeds the regulatory threshold by only a small value. Conversely, a "large-value" failure would be defined as one in which the prediction from site characterization was below threshold when, in fact, the actual contamination level exceeded the regulatory threshold by a large amount.

The values of $\$ a, \$ b, \$ c$ and $\$ d$ are arbitrary, but they follow the logic of a small penalty $(\$ a)$ for small errors, and a large penalty $(\$ b)$ for large errors that could be construed as "flagrant." This approach is consistent with the power-curve concept related to the data-quality-objective process published by the U.S. Environmental Protection Agency (EPA, 1993). If the small errors are so abundant as to constitute "negligence," an additional one-time cost of failure $(\boldsymbol{\$ c})$ is assessed as a penalty. A complete breakdown of an alternative characterization program resulting in an unacceptably large number of largevalue failures is penalized by a very large cost of failure $(\boldsymbol{\phi} d)$.

We have elected to set $\$ a=C t r e a t$, in keeping with a philosophy that a few small errors do not constitute systematic failure of the characterization effort. Because failure $\operatorname{cost} \$ \boldsymbol{a}$ is intended merely to include the cost of after-the-fact treatment, it is necessary to accrue this cost for every parcel that fails. Similar logic applies to failure cost $\$ b$, only in this case the cost is higher to cover expenses associated with additional sampling and paperwork intended to assure the regulatory body that such large-value errors are relatively isolated occurrences. Failure costs $\$ c$ or $\$ d$ are assumed to be incurred only once.

\subsection{STOCHASTIC EVALUATION OF THE OBJECTIVE FUNCTION}

The objective function for the decision model (equation 1) was evaluated using the logic presented in figure 2 . There are several important features about this formulation of the stochastic approach that follow from stochastic simulation of the ground-truth model. (1) The loop structure focuses on the uncertainty and the expected cost associated with each remediation panel, $\mathbf{x}$. Thus, although the comparison of $\Phi_{i}$ is technology by technology, preservation and appropriate presentation of the intermediate, $\mathbf{x}$-subscripted results allows direct spatial mapping of dollars for any technology, $i$. This illustrative 
technique may be very effective for communicating comparisons, particularly to lay audiences. (2) It is possible to iterate over several probability levels and to plot $E\{C t o$ $\left.t_{a l_{i}}\right\}$ as a function of $p$ to identify any prominent break in slope (change in behavior). (3) It is also possible to iterate over several remediation threshold values, $Z^{*}$, to demonstrate changes in $E\left\{\right.$ Ctotal $\left._{i}\right\}$ or differences in technology ranking as a function of clean-up threshold.

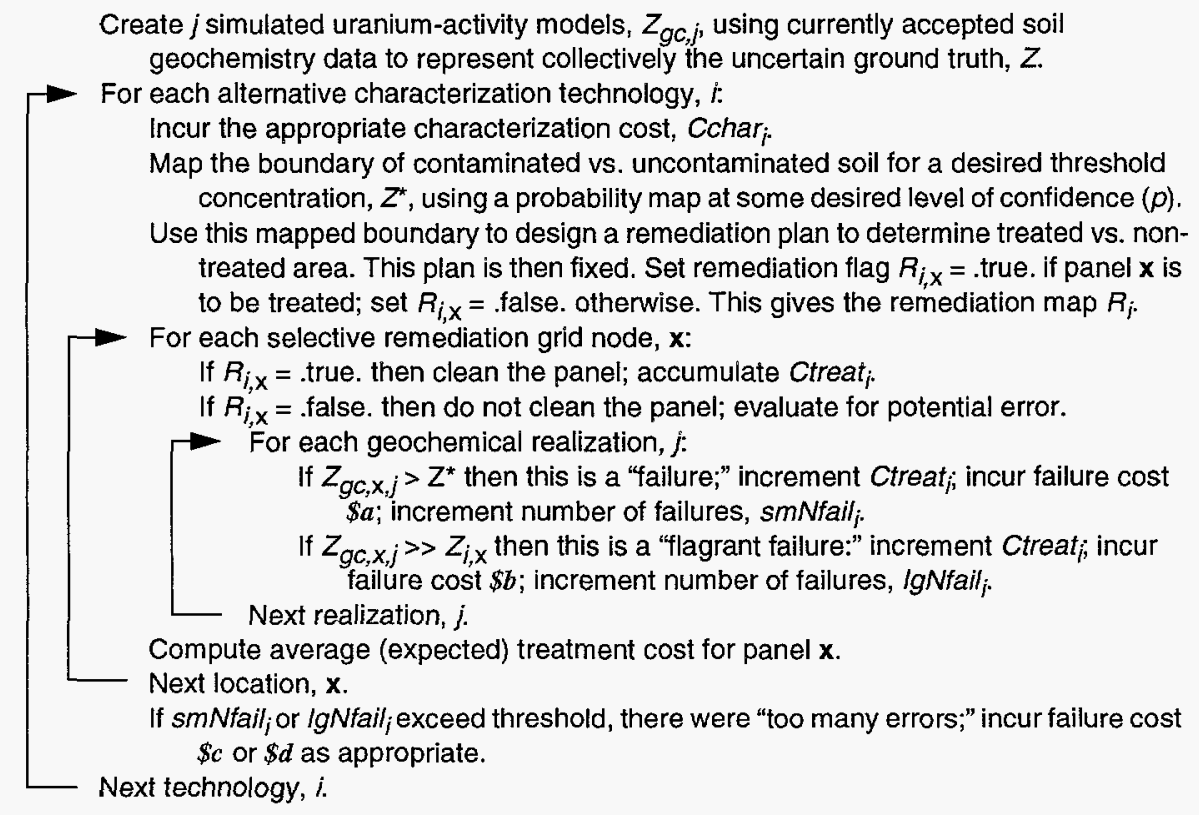

Figure 2. Pseudo-computer-code algorithm for stochastic evaluation of the objective function in the economic decision model using geostatistical simulation to capture uncertainty in the actual level of uranium

\section{Results}

The values of the objective function, $\Phi_{i}$, that result from the stochastic comparison of the alternative characterization methods at three different action levels and one specific probability level are presented in figure 3; the different components of the objective function are indicated. Note that the value of the objective function, and the ranking of the technologies, varies depending upon the question being asked (the specified action level). The total expected costs to remediate the site for an action level of $60 \mathrm{pCi} / \mathrm{g}$, including the likely cost of regulatory failure, vary by a factor of 2 from $\$ 554,000$ (Beta) to more than $\$ 1.24$ million (ATD and EIC). The cost of treatment alone varies from a low of $\$ 57,000$ to the a priori full-site treatment cost of $\$ 880,992$ (2016 panels $@ \$ 437)$. The lowest-treatment-cost option resulted from use of the EIC characterization methodology, which was one of the relatively low cost innovative demonstration techniques. However, despite the low characterization and indicated treatment costs, this method is actually the 
overall most expensive alternative because of the high probability of failure. Note that four characterization technologies (FID, LRAD, NAD, XRF) are associated with a zero expected cost of failure. Each of these methods indicated that the entire site is contaminated. Conversely, the ATD technology indicated virtually no contamination and thus its costs are overwhelmingly related to regulatory failure.
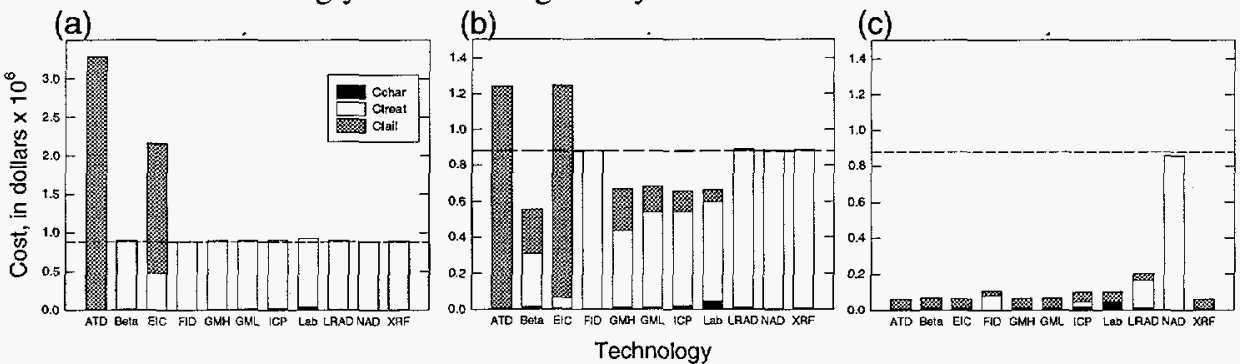

Figure 3. Components of the objective function value $\left(\Phi_{i}\right)$ for the 11 different characterization technologies at a probability level of 0.30 and a uranium action threshold of (a) $35 \mathrm{pCi} / \mathrm{g}$, (b) $60 \mathrm{pCi} / \mathrm{g}$, and (c) $100 \mathrm{pCi} / \mathrm{g}$. Horizontal line is the a priori cost to treat the entire site. Note expanded cost scale in (a).

Comparison of the different characterization techniques is expanded in figure 4 , in which the value of $\Phi_{i}$ is shown as a function of the probability level $(p)$ used to define the remediation plan. If the site operator is unwilling to accept any risk of an incorrect remediation decision, $p$ is equal to zero and there is no alternative to treating the entire site area. Characterization in this case is worthless, and the cost of conducting characterization activities is in addition to the zero-risk cost of treatment. As the probability level acceptable to the site operator increases (the operator becomes less risk-averse), figure 4 indicates that $\Phi=$ Ctotal typically decreases. There are two characterization technologies for which this reduction in the value of the objective function does not occur: the ATD and EIC methodologies. These two alternative technologies are adaptations of indoor radon-monitoring devices, and their performance has been documented as notably inaccurate and sensitive to changes in environmental conditions in the field (Rautman, 1996).
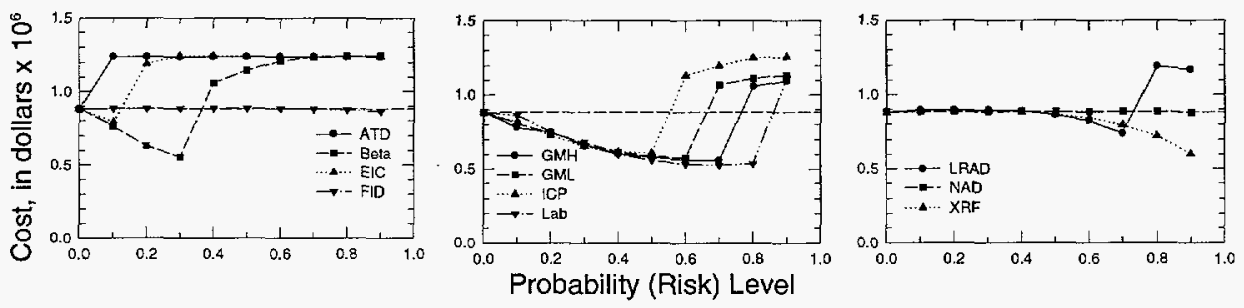

Figure 4. Objective function values $\left(\Phi_{j}\right)$ for the different field-characterization technologies as a function of probability level for a uranium action threshold of $60 \mathrm{pCi} / \mathrm{g}$. Horizontal line is a priori cost to treat entire site.

Figure 4 also indicates that at some increased probability level, Ctotal begins to increase abruptly. This increase reflects the changing interplay of the likely costs of treatment and failure with changes in probability level that determine the initial remediation plan. The individual cost components that result from this trade-off between Ctreat 
and $\mathrm{E}\{C f a i l\}$ are shown in figure 5 for three of the characterization technologies. These graphs emphasize that one can only achieve a net reduction in total remediation cost by trading part of the cost of treatment for a finite probability of failure corresponding to a non-zero $\mathrm{E}\{C f a i l\}$. At some probability level, the likelihood of failure simply becomes too great, and it is cheaper simply to clean up the parcel and be done with it. Note however, that very low probability levels, perhaps corresponding to the "95-percent confidence level" of classical statistics, may not be the most cost-effective level of site characterization and remediation.
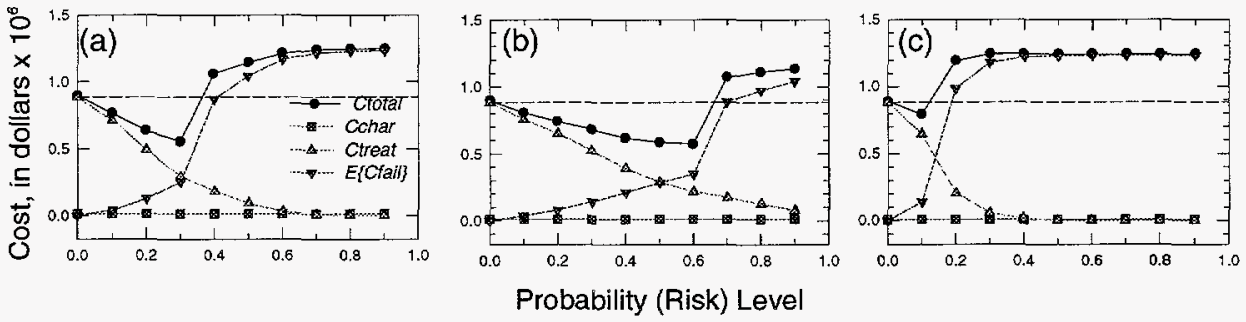

Figure 5. Individual cost curves for three technologies: (a) beta scintillometer, (b) low-mount gamma-ray spectrometer, and (c) electret-ionization chambers. Horizontal line is a priori cost to treat entire site.

(a)

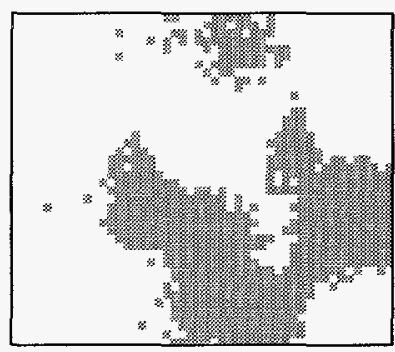

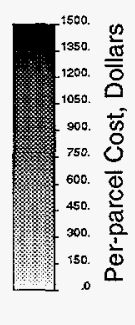

(b)

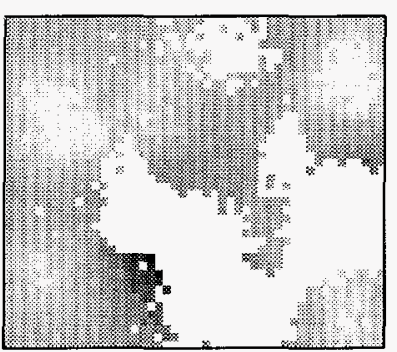

Figure 6. Maps showing the spatial distribution of (a) Ctreat and (b) $\mathrm{E}\{\mathrm{Cfail}\}$ for the beta scintillometer characterization technique at a probability level of 0.30 ; action level $60 \mathrm{pCi} / \mathrm{g}$.

Maps of the per-parcel expected costs are shown in figure 6 for the lowest-cost characterization alternative (Beta). Figure 6(a) simply indicates the initial remediation plan developed using probability mapping of the Beta scintillometer data at the minimumcost probability level of 0.30 . The cost of treatment is presumed constant at $\$ 437$ per parcel. Figure 6(b) presents the spatially variable per-parcel expected cost of failure. The white areas correspond exactly to the grey parcels in figure 6(a). This map of figure 6(b) clearly contains information relevant to continued site characterization at this site. The darker parcels are those associated with the highest expected cost of failure, up to nearly $\$ 1,500$ per parcel. Because the combined cost of taking an additional sample and cleaning up that parcel is only $\$ 167+\$ 437=\$ 604$, one should be able to reduce the total expected cost through additional sampling in regions where the E\{Cfail\} exceeds this amount. Note that because of spatial correlation, a single additional sample probably will provide information about more than one remediation unit. 


\section{Conclusions}

A quantitative cost-risk decision framework using geostatistical simulation to quantify uncertainty related to less-than-exhaustive site characterization can be used to identify cost-effective plans for environmental remediation. This framework has been demonstrated for the problem of selecting among alternative technologies for measuring the uranium activity of in-situ soils adjacent to an aerosol contamination source at the U.S. Department of Energy Fernald (Ohio USA) site. The decision framework involves minimizing the total expected cost of site characterization, site treatment, and potential regulatory failure to clean the site to established standards across a reasonable number of engineering alternatives. The preferred alternative technology has been shown to be a function of the regulatory action level and the degree of risk-aversion of the decision maker. The lowest total-cost alternative may not be associated with the lowest probability of making incorrect treat vs. leave-in-place decisions for individual remediation units. Characterization, treatment, and potential failure costs vary spatially, and maps of these likely costs can provide useful information with respect to staged sampling efforts and stopping criteria for site characterization work.

\section{References}

Deutsch, C.V., and Journel, A.G., 1992, GSLIB Geostatistical software library and user's guide, New York: Oxford University Press, $340 \mathrm{p}$.

DOE (U.S. Department of Energy), 1992, Contaminated soils adjacent to the sewage treatment plant incinerator, removal action \# 14 work plan, U.S. Department of Energy, Cincinnati, Ohio.

Douthat, D.M., Steward, R.N., and A.Q. Armstrong, 1995, Cost results from the 1994 Fernald characterization field demonstration for uranium-contaminated soils: Report ORNL/TM-12985, Oak Ridge National Laboratory, Oak Ridge, Tenn., 20 p.

EPA (U.S. Environmental Protection Agency), 1993, Data quality objectives process for Superfund, Interim final guidance 9355.9-01, EPA540-R-93-071, PB94-963203, U.S. Environmental Protection Agency, Office of Emergency and Remedial Response.

Freeze, R.A., Massmann, J,, Smith, L., Sperling, T, and James, B., 1990, Hydrogeological decision analysis: 1. A framework: Ground Water, v. 28, p. 738-766.

Rautman, C.A., McGraw, M.A., Istok, J.D., Sigda, J.M., and Kaplan, P.G., 1994, Probabilistic comparison of alternative characterization technologies at the Fernald Uranium-in-Soils Integrated Demonstration Project, in Proceedings of Waste Management-94, Tucson, Ariz., February 27-March 3, 1994, p. 2117 2124.

Rautman, C.A., Cromer, M.V., Newman, G.C., and Beiso, D.A., 1995, 1994 Fernald Field Demonstration Program Data Report: Sandia Report SAND95-3024, Sandia National Laboratories, Albuquerque, N.Mex., $170 \mathrm{p}$.

Rautman, C.A., 1996, Evaluation of measurement reproducibility using the standard-sites data, 1994 Fernald field characterization demonstration program: Sandia Report SAND96-0262, Sandia National Laboratories, Albuquerque, N.Mex., 38 p.

Schilk, A.J., Perkins, R.W., Abel, K.H., and Brodzinski, RL., 1993, Surface and subsurface characterization of uranium contamination at the Fernald environmental management site, Report PNL-8617, Pacific Northwest Laboratory, Richland, Wash., 43 p. 


\section{DISCLAIMER}

This report was prepared as an account of work sponsored by an agency of the United States Government. Neither the United States Government nor any agency thereof, nor any of their employees, makes any warranty, express or implied, or assumes any legal liability or responsibility for the accuracy, completeness, or usefulness of any information, apparatus, product, or process disclosed, or represents that its use would not infringe privately owned rights. Reference herein to any specific commercial product, process, or service by trade name, trademark, manufacturer, or otherwise does not necessarily constitute or imply its endorsement, recommendation, or favoring by the United States Government or any agency thereof. The views and opinions of authors expressed herein do not necessarily state or reflect those of the United States Government or any agency thereof. 